\title{
Diurnal variations in middle-atmospheric water vapor by ground-based microwave radiometry
}

\author{
D. Scheiben, A. Schanz, B. Tschanz, and N. Kämpfer \\ Institute of Applied Physics, University of Bern, Switzerland \\ Oeschger Centre for Climate Change Research, University of Bern, Switzerland \\ Correspondence to: D. Scheiben (dominik.scheiben@iap.unibe.ch) \\ Received: 10 December 2012 - Published in Atmos. Chem. Phys. Discuss.: 12 February 2013 \\ Revised: 31 May 2013 - Accepted: 18 June 2013 - Published: 23 July 2013
}

\begin{abstract}
In this paper, we compare the diurnal variations in middle-atmospheric water vapor as measured by two groundbased microwave radiometers in the Alpine region near Bern, Switzerland. The observational data set is also compared to data from the chemistry-climate model WACCM. Due to the small diurnal variations of usually less than $1 \%$, averages over extended time periods are required. Therefore, two time periods of five months each, December to April and June to October, were taken for the comparison.

The diurnal variations from the observational data agree well with each other in amplitude and phase. The linear correlation coefficients range from 0.8 in the upper stratosphere to 0.5 in the upper mesosphere. The observed diurnal variability is significant at all pressure levels within the sensitivity of the instruments. Comparing our observations with WACCM, we find that the agreement of the phase of the diurnal cycle between observations and model is better from December to April than from June to October. The amplitudes of the diurnal variations for both time periods increase with altitude in WACCM, but remain approximately constant at $0.05 \mathrm{ppm}$ in the observations.

The WACCM data are used to separate the processes that lead to diurnal variations in middle-atmospheric water vapor above Bern. The dominating processes were found to be meridional advection below $0.1 \mathrm{hPa}$, vertical advection between 0.1 and $0.02 \mathrm{hPa}$ and (photo-)chemistry above $0.02 \mathrm{hPa}$. The contribution of zonal advection is small. The highest diurnal variations in water vapor as seen in the WACCM data are found in the mesopause region during the time period from June to October with diurnal amplitudes of $0.2 \mathrm{ppm}$ (approximately $5 \%$ in relative units).
\end{abstract}

\section{Introduction}

The dynamical regime of the middle atmosphere is dominated by global-scale waves with large amplitudes, and most of the observed spatiotemporal variability in winds, temperature and constituent concentrations is due to these wave motions (Pancheva and Mukhtarov, 2011). One type of wave motions is atmospheric tides, originating from the periodic solar heating of the stratospheric ozone layer and from latent heat release in the troposphere. These tidal waves propagate in the whole atmosphere, and their amplitudes increase with altitude due to the decreasing density of air. Atmospheric tides are usually divided into migrating and nonmigrating tides. Sun-synchronous waves are called migrating tides and propagate westward with the apparent motion of the sun, and all tides that are not sun-synchronous are called non-migrating tides. The sun-synchronous waves with zonal wavenumbers 1 and 2 are the most studied atmospheric tides (Chapman and Lindzen, 1970; Forbes and Garret, 1979 as cited by Pancheva and Mukhtarov, 2011) and are denoted as diurnal and semidiurnal migrating tides, respectively.

Various previous studies on atmospheric tides focus on the mesosphere and lower-thermosphere (MLT) region since the tidal amplitudes maximize in this region. Observational studies on tides in temperature and wind in the MLT region were done with satellite instruments (e.g., Forbes and Wu, 2006; Zhang et al., 2006) and from ground-based wind and temperature measurements (meteor radars and lidars) (e.g., Vincent et al., 1988; Smith et al., 2007; Lu et al., 2011; Lübken et al., 2011). The main advantages of satellite instruments are their global coverage and the ability to separate migrating and non-migrating tides. On the other hand, the orbital 
parameters of satellite instruments often constrain the observations to a fixed local solar time. Ground-based instruments provide a continuous data set at a fixed location, allowing a detailed study of the diurnal variability at the measurement location. However, global data sets are needed to draw conclusions about the characteristics of the observed tides. Numerical models have also been used to study the tidal behavior of the atmosphere (e.g., Hagan et al., 1995; McLandress, 1997; Smith et al., 2003; Morel et al., 2004; Chang et al., 2008). In order to validate and improve such models, observations are required. Since atmospheric tides in trace species are a combination of dynamical and (photo-)chemical processes, their investigation and validation with observations provide helpful information to improve numerical models.

This study focuses on diurnal variations in water vapor from the upper stratosphere to the upper mesosphere as observed by two independent ground-based microwave radiometers located in the Alpine region. Ground-based microwave radiometry is a well-established and approved remote-sensing technique commonly used to derive trends in atmospheric trace species (e.g., Seele and Hartogh, 2000; Nedoluha et al., 2003; Hartogh et al., 2010, 2011) in order to study anomalies during extreme events such as sudden stratospheric warmings (e.g., Flury et al., 2009; Scheiben et al., 2012) or intraseasonal oscillations of trace species (e.g., Studer et al., 2012). So far, there have been two observational studies on diurnal variations in middle-atmospheric water vapor. The first study was done by Haefele et al. (2008) with observations from the same microwave radiometer as used in this study. However, this radiometer has been technically upgraded, resulting in a better temporal resolution and increased altitude range. A second study was done by Hallgren and Hartogh (2012) with data from a ground-based microwave radiometer in the polar region. The present study compares diurnal variations in middle-atmospheric water vapor from two independent radiometers at the same site as each other to enhance confidence in the derived observational diurnal variations. In addition, the observations are compared with diurnal variations in water vapor from the Whole Atmosphere Community Climate Model (WACCM).

The paper is structured in the following way: Sect. 2 describes the instruments, WACCM and the used methods to derive the diurnal variations from these data sets. In Sect. 3, the results from the different data sets are presented for two time periods and the discussion follows in Sect. 4. In Sect. 5, a summary is given.

\section{Data and methods}

\subsection{Observational data}

The observational water vapor data are obtained by two ground-based microwave radiometers. One of the two radiometers, MIAWARA (MIddle Atmospheric WAter va- por RAdiometer), is a stationary instrument and has been operating continuously in Zimmerwald, Bern, Switzerland $\left(46.88^{\circ} \mathrm{N} / 7.47^{\circ} \mathrm{E}\right)$, since 2007 in the frame of the Network for the Detection of Atmospheric Composition Change (NDACC). The other instrument, MIAWARA-C, was built in 2008 , has a very compact design and is used for measurement campaigns. Both radiometers measure the brightness temperature around the pressure broadened rotational transition line of water vapor at $22.235 \mathrm{GHz}$ with a fast Fourier-transform spectrometer (FFTS). The measured spectrum is inverted to a vertical water vapor profile by the optimal estimation method (OEM) (Rodgers, 2000) using the radiative transfer model ARTS/QPack (Eriksson et al., 2011). A detailed description of the two instruments is given in Deuber et al. (2004) and Straub et al. (2010) for MIAWARA and MIAWARA-C, respectively. The vertical range of the instruments is between 35 and $75 \mathrm{~km}$ altitude and the vertical resolution (full width at half maximum of the averaging kernels) ranges from $13 \mathrm{~km}$ at $40 \mathrm{~km}$ altitude to $17 \mathrm{~km}$ at $70 \mathrm{~km}$ altitude. The systematic error is approximately $10 \%$ at all altitudes, and the random error increases from $5 \%$ at $45 \mathrm{~km}$ to approximately $25 \%$ at $75 \mathrm{~km}$.

MIAWARA was upgraded in September 2010 by replacing the stepper motor for the rotating mirror and improving the calibration cycle. The aim of the upgrade was to increase the effective measurement time, resulting in an increase of the temporal resolution of the retrievals. The other instrument, the campaign instrument, was measuring in Zimmerwald next to MIAWARA from July 2010 until May 2011. During the stay in Zimmerwald, MIAWARA-C was also upgraded in December 2010. Before the upgrade, it was not possible to retrieve more than five profiles per day, but after the upgrade, more than 10 profiles per day are obtained during $80 \%$ of the measurement days (Tschanz et al., 2013). The improvement in temporal resolution of the instruments after the technical upgrades allows derivation of the diurnal variations in water vapor based on the FFTS. It must be noted that the previous study by Haefele et al. (2008) derived diurnal variations with the MIAWARA radiometer before the technical upgrade, but with an acousto-optical spectrometer (AOS). The AOS had a spectral resolution of $612 \mathrm{kHz}$, i.e., coarser than the FFTS of MIAWARA by factor of 10, and those measurements where less noisy due to the coarser resolution. Therefore, it was possible to obtain a temporal resolution on the order of hours even before the technical upgrade. However, retrievals based on the AOS had an upper measurement limit of $0.1 \mathrm{hPa}$.

The retrieval setup is the same for both instruments. The spectral bandwidth used in the retrieval is $100 \mathrm{MHz}$ $( \pm 50 \mathrm{MHz}$ around $22.235 \mathrm{GHz}$ ). For MIAWARA, the spectral resolution is $61 \mathrm{kHz}$, and for MIAWARA-C, the spectral resolution is $30.5 \mathrm{kHz}$. For every retrieval, the measured and calibrated spectra are integrated until they reach a noise level of $0.01 \mathrm{~K}$. Depending on tropospheric opacity, the required measurement time for such an integrated spectrum 
ranges from $1 \mathrm{~h}$ to more than $12 \mathrm{~h}$. Retrievals with a constant measurement noise are preferred in our application because the random errors and the vertical observation range remain almost constant. This is an important issue when averaging individual retrievals. The calibration technique of the instruments can introduce a baseline ripple on the measured spectrum. Such a baseline ripple varies over time, depending mainly on tropospheric opacity. To reduce these baseline artifacts, a polynomial fit of order 3 and a sinusoidal fit with six periods are applied to the measurement as part of the optimal estimation procedure (QPack user guide on http://www.sat.ltu.se/arts/docs/). To determine the sinusoidal periods, a first retrieval is performed without a sinusoidal fit. Based on this first retrieval, we apply a least-squares fitting method with six sinusoidal terms on the difference between the measured spectrum and the forward model. The determined dominant sinusoidal periods are then passed to QPack to perform the OEM including the sinusoidal fit. The baseline fit leads to a loss of measurement sensitivity at lower altitudes and is the main reason why the instruments are not sensitive below $35 \mathrm{~km}$ altitude. We define the measurement sensitivity as acceptable where the area of the averaging kernels exceeds 0.8 . The magnitude of sinusoidal oscillations on the measured spectrum is usually smaller than $0.02 \mathrm{~K}$, i.e., one order of magnitude smaller compared to the signal of the rotational transition line of water vapor. The temperature profile is taken from the operational analysis of the European Centre for Medium-Range Weather Forecasts (ECMWF), considering also the diurnal variations in temperature. The a priori water vapor profile required by OEM is a monthly climatology of water vapor profiles from the Microwave Limb Sounder (MLS) onboard NASA's Aura satellite.

To derive diurnal variations of water vapor with magnitudes of approximately $1 \%$, averages over a time period of several months are required to obtain statistically significant results. The errors of the derived diurnal variations are calculated by dividing the total error (observational and smoothing error) of the individual measurements by the square root of the number of measurements. The present results are obtained by post-upgrade measurements of both radiometers at the same site; that is, from December 2010 until April 2011 in Zimmerwald. For the stationary instrument MIAWARA, the measurements from the consecutive year, i.e., from December 2011 until April 2012, are also considered. Results for MIAWARA are also shown for a time period shifted by 6 months, i.e., from June to October for the years 2011 and 2012. The observational results are compared to model data. It will be shown by the model data that the phase and amplitude of the diurnal variations of water vapor do not change considerably over the different months within one time period.

\subsection{Model data}

The model data for water vapor used in this study are from WACCM. The model was developed at the National Center for Atmospheric Research (NCAR) in Boulder, Colorado. As a numerical framework, WACCM uses the NCAR Community Earth System Model (CESM), which is a fully-coupled, global climate model. It consists of individual land, ice, ocean and atmosphere models. WACCM has an excellent fast chemistry and a high accuracy of photolysis rates (SPARC CCMVal, 2010). In this study, we use version 4 of WACCM. The model has 66 vertical levels on hybrid coordinates with the upper model limit at approximately $140 \mathrm{~km}$ altitude. The horizontal resolution is $5^{\circ}$ in longitude and $4^{\circ}$ in latitude. The model time step for the simulation run was $15 \mathrm{~min}$ and the simulation was performed for one model year. The atmospheric model is free-running and the ocean is prescribed by climatological data from the year 2000. Free-running means that the temporal evolution of the atmosphere is solely bound to the laws of physics and that the real atmospheric state differs from the model data for any particular time. WACCM simulates the interaction between radiation, chemistry and dynamics for the whole atmosphere and is therefore capable of modelling diurnal variations in trace species such as water vapor. Since the focus of this study is on diurnal deviations from mean values, these model data are taken as a representative climatological mean for the diurnal variations in the middle atmosphere. To compare the model data with the observations, the model data were interpolated to the location of the two radiometers. Since the model has a higher vertical resolution compared to the observational data, the model data were convolved with the averaging kernels of the microwave radiometers for a proper comparison of the individual data sets.

\subsection{Deriving the diurnal variations}

In a first step in deriving the diurnal variations of water vapor, a 1-day running mean is subtracted from the water vapor time series to remove any trends or periodicities with periods longer than one day. In a second step, the $24 \mathrm{~h}$ of a day are divided into twelve $2 \mathrm{~h}$ bins and every detrended water vapor profile is attributed to the corresponding $2 \mathrm{~h}$ bin. Then, the profiles within each $2 \mathrm{~h}$ bin are averaged and subtracted by the average profile of all $2 \mathrm{~h}$ bins. For the model data on an equally spaced time grid, this procedure is straightforward, but the observational water vapor data from the ground-based radiometers MIAWARA and MIAWARA-C are neither obtained in regular time steps nor do the retrievals cover constant time periods. Therefore, each retrieved water vapor profile is attributed to one or more $2 \mathrm{~h}$ bins, depending on the actual measurement duration. In addition, a weighting factor of $1 /(\#$ of covered $2 \mathrm{~h}$ bins) is applied such that a retrieval is equally distributed among the $2 \mathrm{~h}$ bins. By doing so, a retrieval that covers only one $2 \mathrm{~h}$ bin is more strongly 
weighted for that bin than a retrieval covering more than one $2 \mathrm{~h}$ bin.

\subsection{Chemical and dynamical contribution}

With the WACCM model, the chemical and the dynamical contribution to the diurnal variations in middle-atmospheric water vapor can be separated. The material derivative for an atmospheric trace species is

$\frac{\mathrm{d} \psi}{\mathrm{d} t}=\frac{\partial \psi}{\partial t}+u \frac{\partial \psi}{\partial x}+v \frac{\partial \psi}{\partial y}+w \frac{\partial \psi}{\partial z}$,

where $\psi$ in our case is the water vapor volume mixing ratio (VMR), $t$ is time and $u, v$ and $w$ are the zonal, meridional and vertical winds. The total derivative is the temporal change of water vapor from a Lagrangian perspective and is the sum of the chemical net production and phase changes of water vapor. In the altitude region of interest, phase changes of water vapor can be neglected. The first term on the right-hand side, the local derivative, is the temporal change in water vapor at a fixed position. This is what a ground-based instrument observes. The remaining terms on the right-hand side determine how the temporal changes in water vapor are modulated due to zonal, meridional and vertical advection. The terms on the right-hand side of Eq. (1) can be calculated directly from the model output. To derive the relative contribution of each term with respect to the diurnal variation of water vapor at a fixed location, each term of Eq. (1) is integrated in time, which yields individual time series of water vapor due to chemistry and zonal, meridional and vertical advection. The diurnal variations of these individual time series (calculated according to Sect. 2.3) are fitted by a sine wave with a period of 1 day. The amplitudes of the sine fit denote the diurnal amplitudes in water vapor due to each individual process, and they are compared to each other.

\section{Results}

\subsection{Comparison between observational and model data}

Figure 1 shows the diurnal variations in water vapor VMR as described in Sect. 2.3 for the months December to April, observed by MIAWARA and MIAWARA-C and simulated by WACCM for the measurement location of the ground-based instruments. The lowermost panel in the figure shows the correlation coefficients between the observational and the convolved WACCM data. In the following description, we are continuously going down in altitude from the upper mesosphere to the upper stratosphere. At the upper measurement limit of the observations, i.e., at $0.02 \mathrm{hPa}$, water vapor has a maximum during the morning and a minimum during the evening. Going down in altitude, there is an abrupt phase shift above $0.03 \mathrm{hPa}$ in the observational data sets by approximately 180 degrees, such that the minimum in water vapor
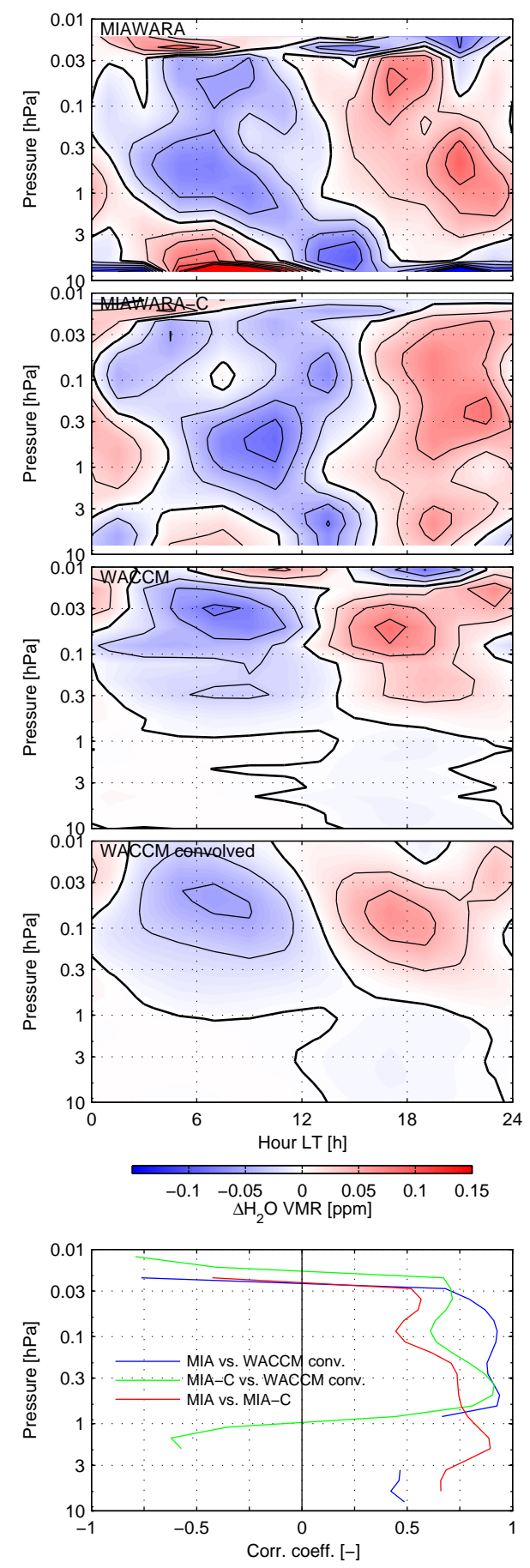

Fig. 1. Diurnal variations of water vapor [ppm] from observational (MIAWARA and MIAWARA-C) and model (WACCM and WACCM convolved) data averaged over the months of December to April. The contour line interval is $0.025 \mathrm{ppm}$. The lowermost panel shows the linear correlation coefficients between the observational and the convolved WACCM data. Correlations are only shown where they exceed $95 \%$ confidence $(p<0.05)$. Times are given in local time. 


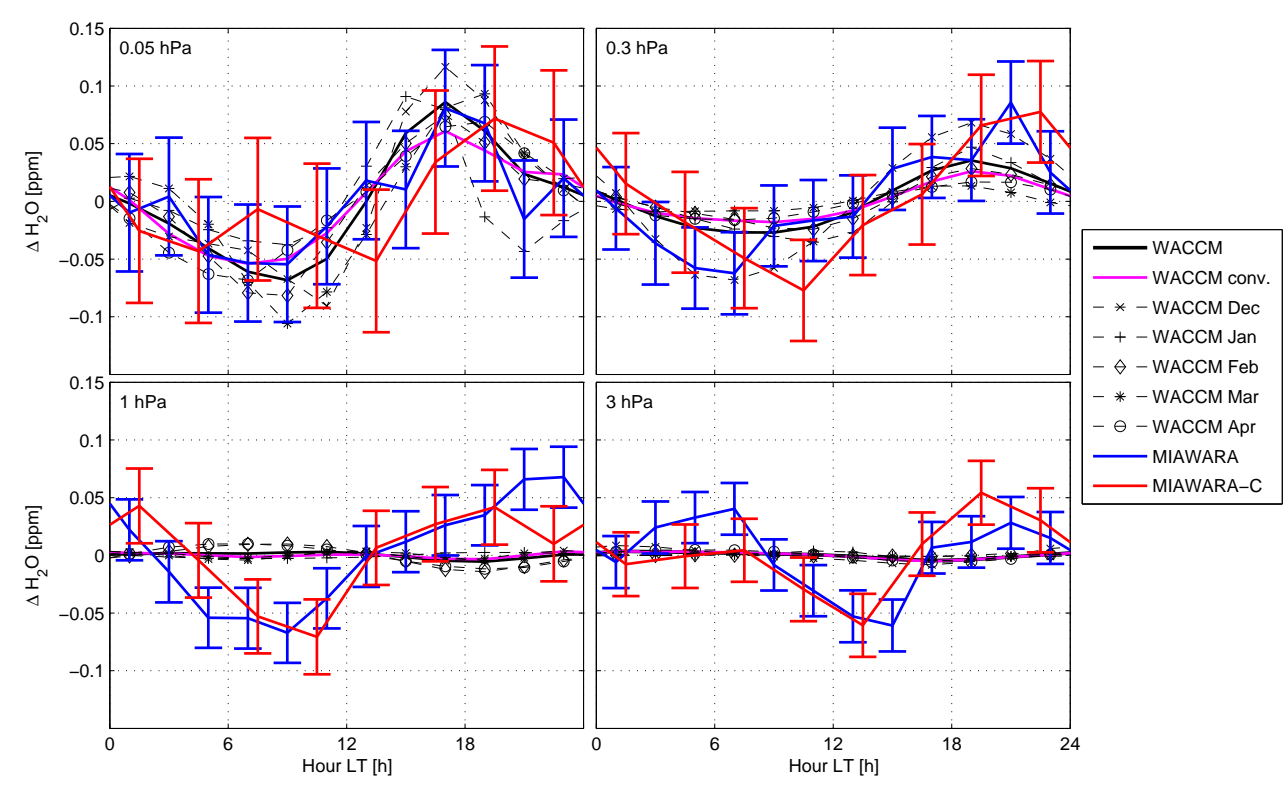

Fig. 2. Diurnal variations of water vapor as in Fig. 1 at four pressure levels $(0.05,0.3,1$ and $3 \mathrm{hPa})$, including error bars for the observational data. The error bars are calculated by dividing the total uncertainty of an individual retrieval by the number of retrievals used for each bin. Systematic errors are not included. The solid black curve represents the 5-month average of the original WACCM data and the magenta curve represents the 5-month average of the convolved WACCM data. Also shown are the individual months (December to April) of the original WACCM data.

is now observed in the morning. WACCM reproduces this phase shift, but it occurs at $0.02 \mathrm{hPa}$, slightly higher than in the observations. In the convolved WACCM data, this phase shift is smoothed out. Throughout the mesosphere, i.e., down to approximately $1 \mathrm{hPa}$, the phase of the diurnal cycle remains constant in each data set. The diurnal amplitude in the observational data remains approximately constant between 0.05 and $0.1 \mathrm{ppm}$ throughout the mesosphere, whereas the amplitude decreases with decreasing altitude in the WACCM data. At the stratopause, there is again a phase shift, such that the minimum in water vapor is now occurring in the evening. This phase shift is very abrupt in the unconvolved and the convolved WACCM data, but smooth in the observational data. Again, this phase shift occurs at higher altitudes in the model data than in the observational data. The amplitude continues to decrease in the WACCM data, but remains constant in the observational data. In the observational data, a semidiurnal tide is also evident in the upper stratosphere (from 2 to $10 \mathrm{hPa}$ ), which is not visible in the model data.

The two observational data sets are correlated over the whole vertical observation range, except at the upper measurement limit, where the sensitivity of the instruments starts to decrease. The correlation coefficients range from 0.8 at the upper stratosphere to 0.5 at the $0.03 \mathrm{hPa}$ pressure level. The correlation between MIAWARA and WACCM is very high in the mesosphere between 0.5 and $0.03 \mathrm{hPa}$, with correlation coefficients higher than 0.8 , but breaks down in the upper mesosphere. In the stratopause region, the correlation breaks down between MIAWARA and WACCM. Be- tween MIAWARA-C and WACCM, the correlation is negative, which is due to the offset in altitude of the phase shift at the stratopause. In the stratosphere, the correlation between MIAWARA and WACCM is positive again, but not as strong as in the mesosphere, whereas MIAWARA-C and WACCM do not show a significant correlation. Overall, MIAWARA shows a slightly better agreement with the model data than MIAWARA-C.

For a better comparison of the diurnal amplitudes among the data sets, Fig. 2 shows the diurnal water vapor variations for the same time period but at four distinct pressure levels, namely at $0.05,0.3,1$ and $3 \mathrm{hPa}$. The plots include error bars for the observational data. The diurnal variations in WACCM are split into the five different months. These months show that there is no major monthly change of the diurnal variation. The diurnal amplitudes in the mesosphere $(0.05$ and $0.3 \mathrm{hPa}$ ) are in the same range for all data sets, and the error bars show that the observed diurnal variability is significant. In the stratopause region $(1 \mathrm{hPa})$ and the upper stratosphere $(3 \mathrm{hPa})$, the amplitudes in the observational data are much larger than in the model data, but still significant according to the error bars.

During the time period from June to October (Fig. 3, analogous to Fig. 1 but without MIAWARA-C), water vapor at the upper limit of the observations has a minimum in the afternoon, just like during the time period from December to April. This is also found in the WACCM data, but the diurnal amplitude in WACCM at this altitude is higher than in the observations. Going down in altitude, the diurnal amplitude 
in the model data decreases strongly, and at $0.03 \mathrm{hPa}$ there is a phase shift in WACCM such that the water vapor minimum is now found in the morning. The diurnal amplitude in WACCM remains very small until $10 \mathrm{hPa}$. The phase shift at $0.03 \mathrm{hPa}$ is seen in the observational data as well, but is less pronounced. In the WACCM data from December to April there is a sharp phase shift at the stratopause region that is also present during the time period from June to October, but occurring at a higher altitude, namely at $0.3 \mathrm{hPa}$. In the observations, this phase shift also occurs, but at a lower altitude (approximately $2 \mathrm{hPa}$ ). Similar to the other time period, the amplitude of the diurnal cycle is larger in the observational data than in the model data, except for the upper mesosphere.

Looking at the individual months in the WACCM data in Fig. 4, one can see that the 5-month average indeed represents each individual month, except that the phase shift in the diurnal variations of water vapor at the stratopause is occurring at different altitudes for each month. The altitude of this phase shift moves upward during the considered time period from June to October.

\subsection{Contribution to the diurnal variations in water vapor according to WACCM}

Based on the WACCM data, the different sources of the diurnal variations in water vapor can be individually calculated (as described in Sect. 2.4). Hereafter, we divide the sources into chemistry and meridional, zonal and vertical advection. Figure 5 shows the diurnal amplitudes of each individual source obtained by least-squares-fitting of a sine wave for the months of December to April (upper panel) and for the month June to October (lower panel). The shown amplitudes denote the amplitude of the fitted sine wave. In addition, the total diurnal amplitude as modeled by WACCM and the diurnal amplitudes as measured by MIAWARA and MIAWARA-C are shown.

From December to April, the diurnal variations in water vapor below $0.03 \mathrm{hPa}$ mainly originate from advection, where meridional advection dominates below $0.1 \mathrm{hPa}$ and vertical advection dominates above $0.1 \mathrm{hPa}$. The influence of (photo-)chemistry increases from $0.1 \mathrm{hPa}$ upwards and dominates over dynamics above $0.02 \mathrm{hPa}$. On $0.01 \mathrm{hPa}$, the diurnal amplitude due to chemistry alone is twice as large as for the vertical advection. The overall diurnal amplitude in water vapor on $0.01 \mathrm{hPa}$ is smaller than the diurnal amplitude due to chemistry alone, meaning that the advection (mainly the vertical advection) damps the diurnal amplitude from the (photo-)chemistry in such a way that the vertical advection transports water-vapor-rich air upward to replace the (photo-)chemically destroyed water vapor. The diurnal cycle in vertical advection in the mesopause region is such that there is upwelling during the day and downwelling during the night. This information is derived from the phase (not shown in the plot) of the fitted diurnal sine wave.
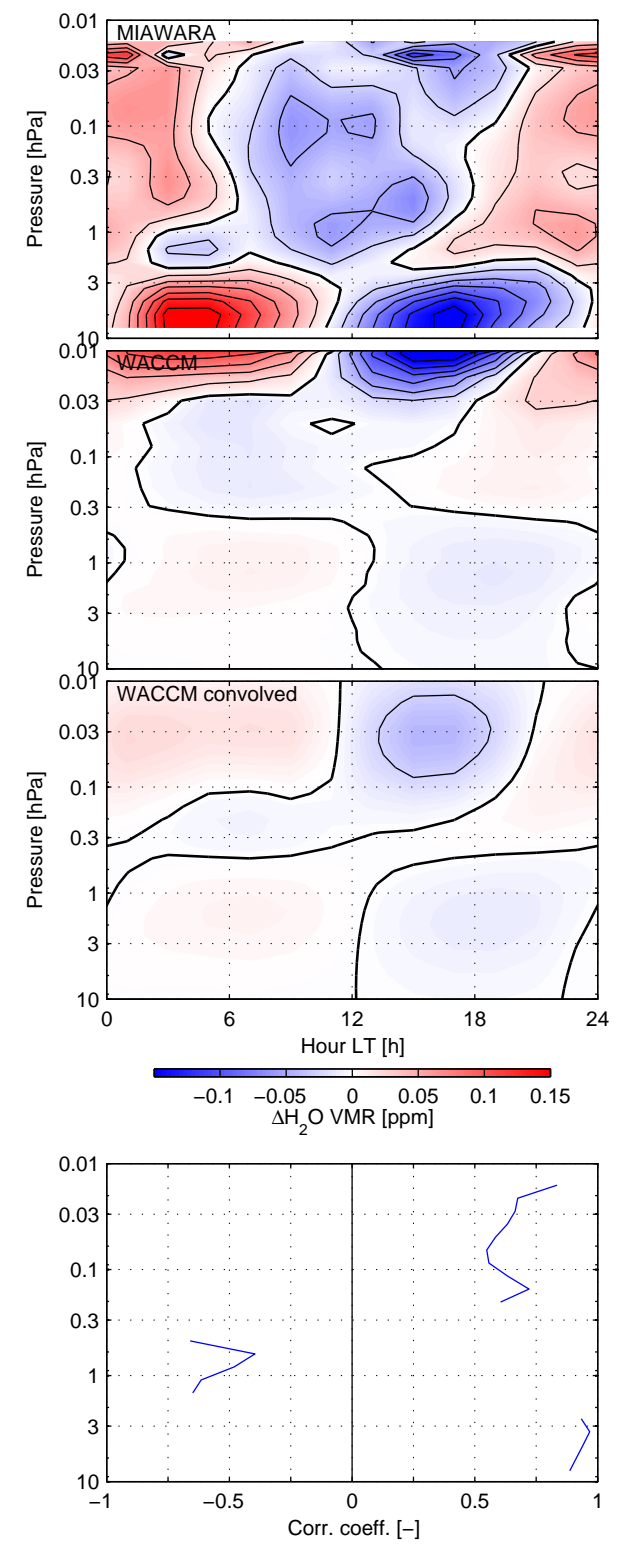

Fig. 3. Diurnal variations of water vapor $[\mathrm{ppm}]$ from observational (MIAWARA) and model (WACCM and WACCM convolved) data averaged over the months June to October. The contour line interval is $0.025 \mathrm{ppm}$. The lowermost panel shows the linear correlation coefficients between MIAWARA and the convolved WACCM data. Correlations are only shown where they exceed $95 \%$ confidence $(p<0.05)$. Times are given in local time.

From June to October, the diurnal variations in water vapor are dominated by meridional advection below $0.1 \mathrm{hPa}$, similar to the other time period, but with larger amplitudes. Above $0.1 \mathrm{hPa}$, vertical advection dominates over meridional advection up to $0.01 \mathrm{hPa}$, from where meridional advection is dominating again. However, the influence of (photo-)chemistry increases strongly with altitude, much stronger than from December to April, and exceeds the 


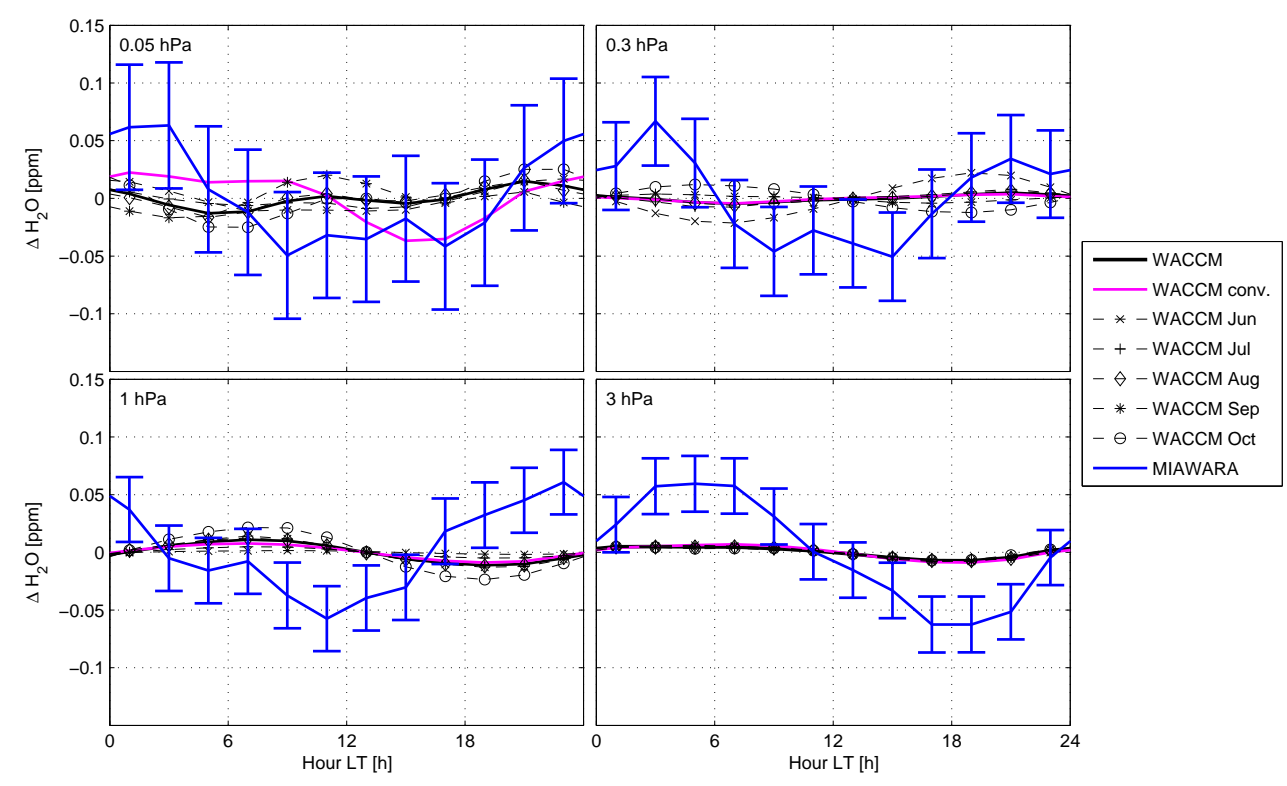

Fig. 4. Diurnal variations of water vapor as in Fig. 3 at four pressure levels $(0.05,0.3,1$ and $3 \mathrm{hPa})$, including error bars for the observational data. The error bars are calculated by dividing the total uncertainty of an individual retrieval by the number of retrievals used for each bin. Systematic errors are not included. The solid black curve represents the 5-month average of the original WACCM data and the magenta curve represents the 5-month average of the convolved WACCM data. Also shown are the individual months (June to October) of the original WACCM data.

dynamical influence above $0.03 \mathrm{hPa}$. At $0.01 \mathrm{hPa}$ and above, the diurnal cycle in water vapor is mainly originating from (photo-)chemistry and reaches amplitudes of $0.2 \mathrm{ppm}$. Compared to the time period from December to April, this is higher by a factor of 4 . However, in relative units, the amplitudes from (photo-)chemistry are approximately the same (not shown) and are in the range of $5 \%$ in the mesopause region, whereas on lower altitudes, the diurnal variations are in the range of $1 \%$.

\section{Discussion}

The observations and the model data show better agreement for the time period from December to April than for the time period from June to October. In fact, good agreement between observations and model in phase and amplitude of the diurnal cycle is only found in the mesosphere above $0.2 \mathrm{hPa}$ between December and April and above $0.03 \mathrm{hPa}$ between June and October. Going down in altitude towards the stratosphere, there are large differences in the amplitude of the diurnal variations between the observations and the model during both considered time periods. The differences between the model data and the observations could originate from various sources. One question that arises is about instrumental artifacts leading to a systematic diurnal cycle in the observations. A good indicator for the reliability of a radiometer is a constant receiver temperature. We did not find any diurnal anomalies in the receiver temperatures of our in- struments. Instrumental calibration parameters with a diurnal cycle could induce systematic diurnal variations in the retrieved water vapor profiles. Such parameters are the calibration target temperatures, the ambient temperature and the tropospheric opacity. Both radiometers perform a balancing calibration, and therefore a tropospheric correction needs to be applied to the measured spectrum. This correction factor depends on the above-mentioned diurnally varying parameters. Since the tropospheric correction factor is scalar, a faulty diurnal variation of this factor would induce a diurnal variation in the retrievals that would be independent of altitude. However, the observational diurnal variations in water vapor are altitude-dependent. Hence, the observed diurnal variations are unlikely to originate from the tropospheric correction factor. Another source of an artificial diurnal cycle in the retrieved water vapor profiles might be the temperature profile used in the retrieval process. The temperature profiles used for this study were taken from ECMWF and averaged over the actual duration of each measurement. There are diurnal variations in the temperature profiles in the order of approximately $5 \mathrm{~K}$ in the mesosphere. We made a distinct retrieval data set without diurnal variations in the temperature profiles and found that the influence of the temperature variation on the retrieved water vapor profiles is very small and that the diurnal variations in water vapor are almost equal for both data sets. A potential diurnal component in the radiometric measurements could arise from the spectral baseline, which mainly affects the retrieval at pressure levels below $1 \mathrm{hPa}$. The instrumental baseline originates mainly from 

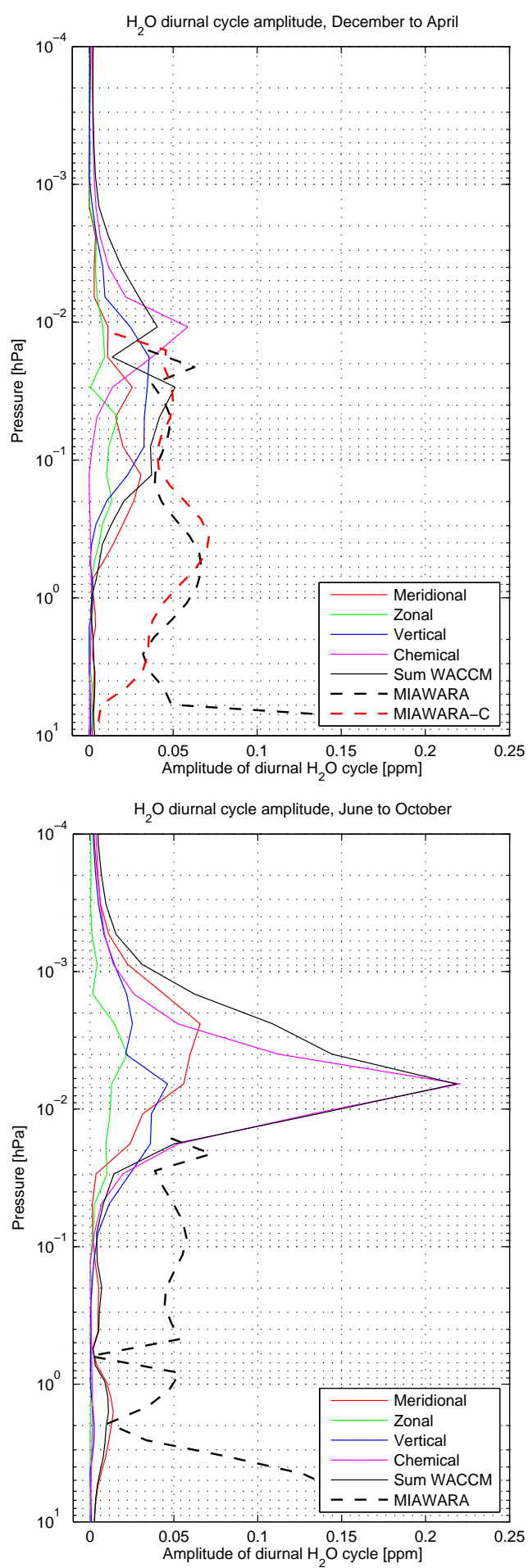

Fig. 5. Amplitudes of the diurnal cycle of water vapor from MIAWARA, MIAWARA-C and WACCM and due to meridional, zonal and vertical advection and (photo-)chemistry (based on the WACCM data). Upper panel: December to April. Lower panel: June to October. MIAWARA-C was not available from June to October. the reference absorber used for the balancing calibration. The diurnally varying solar insolation on the reference absorber could therefore result in a diurnally varying baseline that in turn could lead to artificial diurnal water vapor variations on pressure levels below $1 \mathrm{hPa}$. There are indeed the largest discrepancies between model and observations on pressure levels below $1 \mathrm{hPa}$. Hence, the observations on those altitudes have to be interpreted with care.

An apparent difference between the model and the observational data is the altitude offset of the phase shift in the stratopause region, which is at higher altitudes in the model data. A possible reason for that could be that the water vapor maximum is located at higher levels in WACCM than in the observations. The averaging kernels of the OEM retrievals would not produce such an offset in altitude. It is also not clear why the phase shift in the stratopause region is very sharp in WACCM, even in the convolved WACCM data set, but smooth in the observational data. The averaging kernels are not responsible for the smoothing of this phase shift, because this would be visible in the convolved WACCM data set.

The previous study by Haefele et al. (2008) on diurnal variations in mesospheric water vapor as observed by MIAWARA showed diurnal variations for the months September and October 2005 on 0.1 and $3.14 \mathrm{hPa}$. The phase of the diurnal cycle in their study is similar to the phase obtained in the current study for the months April to October at the same pressure levels, showing a minimum in water vapor during daytime. The amplitude of the diurnal cycle on $3.14 \mathrm{hPa}$ is similar for both studies, but the amplitude on $0.1 \mathrm{hPa}$ is larger in the current study by a factor of 2 . This is due to the fact that the spectral resolution of the spectrometer during the time of the previous study was $612 \mathrm{kHz}$, compared to $61 \mathrm{kHz}$ in the current study. Due to the coarser spectral resolution, the upper measurement limit of the previous study was at approximately $0.1 \mathrm{hPa}$, which results in less sensitive measurements at this pressure level and therefore a smaller diurnal amplitude compared to the current study.

\section{Summary}

In this paper, the diurnal variations in middle-atmospheric water vapor as obtained from two ground-based microwave radiometers in the Alpine region were compared with each other and with WACCM. Due to the small diurnal variations of usually less than $1 \%$, averages over long time periods are used to obtain robust results. Therefore, two time periods were used for the comparison: December to April and June to October.

The two microwave radiometers agree well with each other in amplitude and phase of the diurnal cycle. In the altitude range from $3 \mathrm{hPa}$ to $0.05 \mathrm{hPa}$ the amplitude derived from the observational data is approximately $0.05 \mathrm{ppm}$. The phase changes with altitude. The linear correlation coefficients 
range from 0.8 in the upper stratosphere to 0.5 in the upper mesosphere. Comparing our observations with WACCM, we find that the agreement of the phase of the diurnal cycle between observations and model is better from December to April than from June to October. The amplitudes of the diurnal cycle for both time periods increase with altitude in WACCM, but remain approximately constant in the observations. The discrepancy between modeled and observed diurnal cycle below $1 \mathrm{hPa}$ could be attributed to instrumental effects.

The WACCM data allows separation of the processes leading to diurnal variations in water vapor. The dominating process below $0.1 \mathrm{hPa}$ is meridional advection due to the lack of vertical water vapor gradients. The contribution of zonal advection is small. Between 0.1 and $0.02 \mathrm{hPa}$, vertical advection dominates over meridional advection due to the strong vertical gradient of water vapor in the upper mesosphere. Above $0.02 \mathrm{hPa}$, (photo-)chemistry starts to be the dominating process for the diurnal variations in water vapor. The (photo-)chemical influence on the diurnal amplitude of water vapor from June to October is higher by a factor 4 in absolute units compared to the other analyzed time period. In relative units, the amplitudes are approximately equal.

Acknowledgements. This work has been funded by the Swiss National Science Foundation under grant 200020-146388 and MeteoSwiss in the frame of the project MIMAH. We acknowledge ECMWF for access to the operational analysis data, and NASA for access to Aura MLS data.

Edited by: S. Buehler

\section{References}

Chang, L., Palo, S., Hagan, M., Richter, J., Garcia, R., Riggin, D., and Fritts, D.: Structure of the migrating diurnal tide in the Whole Atmosphere Community Climate Model (WACCM), Adv. Space Res., 41, 1397-1406, doi:10.1016/j.asr.2007.03.035, 2008.

Chapman, S. and Lindzen, R. S.: Atmospheric tides: thermal and gravitational, Gordon and Breach, New York, NY, 1970.

Deuber, B., Kämpfer, N., and Feist, D. G.: A new 22$\mathrm{GHz}$ radiometer for middle atmospheric water vapor profile measurements, IEEE T. Geosci. Remote, 42, 974-984, doi:10.1109/TGRS.2004.825581, 2004.

Eriksson, P., Buehler, S. A., Davis, C. P., Emde, C., and Lemke, O.: ARTS, the atmospheric radiative transfer simulatur, version 2, J. Quant. Spectrosc. Ra., 112, 1551-1558, 2011.

Flury, T., Hocke, K., Haefele, A., Kämpfer, N., and Lehmann, R.: Ozone depletion, water vapor increase, and PSC generation at midlatitudes by the 2008 major stratospheric warming, J. Geophys. Res., 114, D18302, doi:10.1029/2009JD011940, 2009.

Forbes, J. M. and Garret, H. B.: Theoretical studies of atmospheric tides, Rev. Geophys., 17, 1951-1981, 1979.

Forbes, J. M. and Wu, D.: Solar tides as revealed by measurements of mesosphere temperature by the MLS experiments on UARS, J. Atmos. Sci., 63, 1776-1797, 2006.
Haefele, A., Hocke, K., Kämpfer, N., Keckhut, P., Marchand, M., Bekki, S., Morel, B., Egorova, T., and Rozanov, E.: Diurnal changes in middle atmospheric $\mathrm{H}(2) \mathrm{O}$ and $\mathrm{O}(3)$ : Observations in the Alpine region and climate models, J. Geophys. Res., 113, D17303, doi:10.1029/2008JD009892, 2008.

Hagan, M. E., Forbes, J. M., and Vial, F.: On modeling migrating solar tides, Geophys. Res. Lett., 22, 893-896, doi:10.1029/95GL00783, 1995.

Hallgren, K. and Hartogh, P.: First detection of tidal behaviour in polar mesospheric water vapour by ground based microwave spectroscopy, Atmos. Chem. Phys., 12, 3753-3759, doi:10.5194/acp-12-3753-2012, 2012.

Hartogh, P., Sonnemann, G. R., Grygalashvyly, M., Song, L., Berger, U., and Luebken, F. J.: Water vapor measurements at ALOMAR over a solar cycle compared with model calculations by LIMA, J. Geophys. Res., 115, D00I17, doi:10.1029/2009JD012364, 2010.

Hartogh, P., Sonnemann, G. R., Grygalashvyly, M., and Jarchow, C.: Ozone trends in the mid-latitude stratopause region based on microwave measurements at Lindau (51.66 degrees N, 10.13 degrees $\mathrm{E}$ ), the ozone reference model, and model calculations, Adv. in Space Res., 47, 1937-1948, doi:10.1016/j.asr.2011.01.010, 2011.

Lu, X., Liu, A. Z., Oberheide, J., Wu, Q., Li, T., Li, Z., Swenson, G. R., and Franke, S. J.: Seasonal variability of the diurnal tide in the mesosphere and lower thermosphere over Maui, Hawaii (20.7 degrees N, 156.3 degrees W), J. Geophys. Res., 116, D17103, doi:10.1029/2011JD015599, 2011.

Lübken, F. J., Höffner, J., Viehl, T. P., Kaifler, B., and Morris, R. J.: First measurements of thermal tides in the summer mesopause region at Antarctic latitudes, Geophys. Res. Lett., 38, L24806, doi:10.1029/2011GL050045, 2011.

McLandress, C.: Seasonal variability of the diurnal tide: Results from the Canadian middle atmosphere general circulation model, J. Geophys. Res., 102, 29747-29764, doi:10.1029/97JD02645, 1997.

Morel, B., Keckhut, P., Bencherif, H., Hauchecorne, A., Megie, G., and Baldy, S.: Investigation of the tidal variations in a 3-D dynamics-chemistry-transport model of the middle atmosphere, J. Atmos. Sol.-Terr. Phy., 66, 251-265, doi:10.1016/j.jastp.2003.11.004, 2004.

Nedoluha, G., Bevilacqua, R., Gomez, R., Hicks, B., Russell, J., and Connor, B.: An evaluation of trends in middle atmospheric water vapor as measured by HALOE, WVMS, and POAM, J. Geophys. Res., 108, 4391, doi:10.1029/2002JD003332, 2003.

Pancheva, D. and Mukhtarov, P.: Atmospheric Tides and Planetary Waves: Recent Progress Based on SABER/TIMED Temperature Measurements (2002-2007), chap. 2, Aeronomy of the Earth's Atmosphere and Ionosphere, 2011.

Rodgers, C. D.: Inverse Methods for Atmospheric Soundings, World Scientific Publishing Co Pte. Ltd, 2000.

Scheiben, D., Straub, C., Hocke, K., Forkman, P., and Kämpfer, N.: Observations of middle atmospheric $\mathrm{H}_{2} \mathrm{O}$ and $\mathrm{O}_{3}$ during the 2010 major sudden stratospheric warming by a network of microwave radiometers, Atmos. Chem. Phys., 12, 7753-7765, doi:10.5194/acp-12-7753-2012, 2012.

Seele, C. and Hartogh, P.: A case study on middle atmospheric water vapor transport during the February 1998 stratospheric warming, Geophys. Res. Lett., 27, 3309-3312, 
doi:10.1029/2000GL011616, 2000.

Smith, A., Marsh, D., and Szymczak, A.: Interaction of chemical heating and the diurnal tide in the mesosphere, J. Geophys. Res., 108, 4164, doi:10.1029/2002JD002664, 2003.

Smith, A. K., Pancheva, D. V., Mitchell, N. J., Marsh, D. R., Russell, III, J. M., and Mlynczak, M. G.: A link between variability of the semidiurnal tide and planetary waves in the opposite hemisphere, Geophys. Res. Lett., 34, L07809, doi:10.1029/2006GL028929, 2007.

SPARC CCMVal: SPARC Report on the Evaluation of ChemistryClimate Models, edited by: Eyring, V., Shepherd, T. G., and Waugh, D. W.: SPARC Report No. 5, WCRP-132, WMO/TDNo. 1526, 2010.

Straub, C., Murk, A., and Kämpfer, N.: MIAWARA-C, a new ground based water vapor radiometer for measurement campaigns, Atmos. Meas. Tech., 3, 1271-1285, doi:10.5194/amt-31271-2010, 2010.
Studer, S., Hocke, K., and Kämpfer, N.: Intraseasonal oscillations of stratospheric ozone above Switzerland, J. Atmos. Sol.-Terr. Phy., 74, 189-198, doi:10.1016/j.jastp.2011.10.020, 2012.

Tschanz, B., Straub, C., Scheiben, D., Walker, K. A., Stiller, G. P., and Kämpfer, N.: Validation of middle atmospheric campaignbased water vapour measured by the ground-based microwave radiometer MIAWARA-C, Atmos. Meas. Tech. Discuss., 6, 13111359, doi:10.5194/amtd-6-1311-2013, 2013.

Vincent, R. A., Tsuda, T., and Kato, S.: A comparative study of mesospheric solar tides observed at Adelaide and Kyoto, J. Geophys. Res., 93, 699-708, doi:10.1029/JD093iD01p00699, 1988.

Zhang, X., Forbes, J. M., Hagan, M. E., Russell III, J. M., Palo, S. E., Mertens, C. J., and Mlynczak, M. G.: Monthly tidal temperatures $20-120 \mathrm{~km}$ from TIMED/SABER, J. Geophys. Res., 111, A10S08, doi:10.1029/2005JA011504, 2006. 